\title{
Occurrence and removal of pharmaceuticals in wastewater treatment plants at the Spanish Mediterranean area of Valencia
}

\author{
Emma Gracia-Lor, Juan V. Sancho, Roque Serrano and Félix Hernández \\ Research Institute for Pesticides and Water, University Jaume I, Avda. Sos \\ Baynat, E-12071 Castellón, Spain. Tel.: 964 387366. Fax: 964387368.
}

\begin{abstract}
A survey on the presence of pharmaceuticals in urban wastewater of a Spanish Mediterranean area (Castellon province) was carried out. The scope of the study included a wide variety of pharmaceuticals belonging to different therapeutical classes. For this purpose, 112 samples, including influent and effluent wastewater, from different conventional wastewater treatment plants were collected. Two monitoring programmes were carried out along several seasons. The first was in June 2008 and January 2009, and the second in April and October 2009. During the first monitoring, the occurrence of 20 analytes in 84 urban wastewater samples (influent and effluent) was studied. The selection of these pharmaceuticals was mainly based on consumption. From these, 17 compounds were detected in the samples, with analgesics and anti-inflammatories, cholesterol lowering statin drugs and lipid regulators being the most frequently detected groups. 4-Aminoantipyrine, bezafibrate, diclofenac, gemfibrozil, ketoprofen, naproxen and venlafaxine were the compounds most frequently found. In the highlight of these results, the number of analytes was increased up to around 50. A lot of antibiotic compounds were added to the target list as they were considered "priority pharmaceuticals" due to their more potential hazardous effects in the aquatic environment. Data obtained during the second monitoring programme (spring and autumn) corroborated the results from the first one (summer and winter). Analgesics and anti-inflammatories, lipid regulators together with quinolone and macrolide antibiotics were the most abundant pharmaceuticals. Similar median concentrations were found over the year and seasonal variation was not clearly observed. The removal efficiency of pharmaceuticals in the wastewater treatment plants was roughly evaluated. Our results indicated that elimination of most of the selected compounds occurred during the treatment process of influent wastewater, although it was incomplete.
\end{abstract}

\section{Keywords}

Pharmaceuticals; Liquid chromatography-tandem mass spectrometry; Effluent and influent wastewater; Waste water treatment plant; Occurrence; Removal efficiency. 


\section{Introduction}

Pharmaceutical consumption is continuously increasing around the word. Only in Spain, about 729 millions of prescriptions were sold in 2004. Six years later, the consumption increased around $\quad 30 \% \quad$ reaching 958 millions prescriptions (http://www.msps.es/profesionales/farmacia/datos/home.htm). This has lead to an increasing concern regarding possible ecological risks coming from pharmaceuticals released into the environment.

Pharmaceuticals are used extensively in human and veterinary medicine to prevent illness and also as growth promoters in livestock and fish farming as well as in agriculture. After administration, pharmaceuticals can be transformed in the human body into more polar and soluble forms as metabolites or as conjugates of glucuronic and sulphuric acid (Heberer, 2002; Nikolaou et al., 2007). Pharmaceuticals and their metabolites are readily excreted with urine and faeces and enter into urban wastewater treatment plants (WWTPs). Some of these compounds are eliminated by chemical or biological processes while others are degraded during sewage treatment processes or removed from the water phase by adsorption onto solid phase (e.g. sludge) (Jones et al., 2005). Data recently reported show that some pharmaceuticals are accumulated in sewage sludge. This indicates that even good removal rates obtained in aqueous phase (i.e. comparison of influent and effluent wastewater concentrations) do not imply degradation to the same extent. In general, the elimination of most of the substances is incomplete and improvements of the wastewater treatment and subsequent treatments of the produced sludge are required to prevent the introduction of these micropollutants in the environment (Jelic et al., 2011). At present, urban wastewaters are considered the most important source of pharmaceutical compounds in the aquatic environment. WWTPs were designed to remove organic pollutants, mainly estimated as dissolved organic matter, solids and nutrients but not pharmaceutical compounds. Disposal of unused pharmaceuticals directly into domestic waste and application to livestock as veterinary drugs and feed additives can also contribute to their introduction in the environment (Heberer, 2002; Nikolaou et al., 2007).

Removal efficiencies in WWTPs depend on several factors such as compound physicochemical properties, the climate conditions (e.g. temperature and sunlight intensity), the type of treatment process employed, the operational conditions of the treatment process (temperature of operation, redox conditions, solids retention time and hydraulic retention time) as well as the age of the activated sludge used in the plant (Castiglioni et al., 2006; Suárez et al., 2008; LeMinh et al., 2010). Therefore, removal efficiencies can vary significantly from plant to plant and within a plant at different time periods (Vieno et al., 2007).

WWTPs typically employ conventional sewage treatment consisting on primary sedimentation followed by secondary treatment and final sedimentation. Organic pollutants can be transformed from the aqueous phase by hydrolysis, biotransformation or sorption to primary 
and secondary sludges (Le-Minh et al., 2010). However, the removal efficiency is variable as it is highly affected by the compound affinity to remain in the aqueous phase of the treated effluent (hydrophilic pharmaceuticals) or to be adsorbed to sludge (hydrophobic chemicals). In contrast, tertiary treatment or advanced treatment processes such as membrane filtration, activated carbon or oxidative processes (chlorination, ozonation and ultraviolet irradiation) seem to be more efficient when they work under optimum conditions. Nevertheless, their use is not widespread due to their high cost in terms of energy consumption.

Little is known about possible human and ecological adverse effects derived from the presence of pharmaceuticals in the aquatic environment. Although the concentration levels detected after wastewater treatment processes seem not to cause toxic effects on human health and in the aquatic environment, there is a big concern on the long-term exposure of aquatic organisms to pharmaceuticals. Antibiotics are of special interest because they can promote bacterial resistance in the environment due to continuous exposure (Kümmerer, 2009a, 2009b; Zuccato et al., 2010). It is a problematic issue for flora and fauna as well as for humans, especially in those places where treated effluents are used to supplement drinking water supplies (Le-Minh et al., 2010). Consumption on antibiotics varies from country to country. Spain is one of the most consuming countries in terms of total amount. Broad spectrum antibiotics, which have the greatest impact on the development of resistance, are widely consumed according to the European Surveillance of Antimicrobial Consumption (ESAC) homepage (http://app.esac.ua.ac.be/public/index.php/ en_eu/antibiotic/ antibiotic-consumption).

The aim of this paper is to investigate the occurrence and behavior of pharmaceuticals in wastewater treatment plants placed in the Castellon province (Spanish Mediterranean area) in order to have a realistic knowledge of the presence of pharmaceuticals in this region. A total of 112 samples (untreated and treated urban wastewater samples) from three WWTPs were analyzed by liquid chromatography coupled to tandem MS, along two monitoring programmes over the four seasons: summer (June), winter (January), spring (April), and autumn (October). Up to 47 pharmaceuticals were determined including a notable number of antibiotics. The occurrence and removal of these pharmaceuticals in different WWTPs and the effect of the seasonal variation on the elimination of pharmaceuticals was assessed.

\section{Experimental}

\subsection{Reagents and chemicals}

Reference standards were purchased from Sigma-Aldrich (St Louis, MO, USA), LGC Promochem (London, UK), Toronto Research Chemicals (Ontario, Canada), Across Organics (Geel, Belgium), Bayer Hispania (Barcelona, Spain), Fort Dodge Veterinaria (Gerona, Spain), Vetoquinol Industrial (Madrid Spain) and Aventis Pharma (Madrid, Spain). 
Isotopically labeled compounds used were omeprazole- $d_{3}$, acetaminophen- $d_{4}$, diclofenac- $d_{4}$, salicylic acid- $d_{3}$ and ibuprofen- $d_{3}$, from CDN Isotopes (Quebec, Canada); atorvastatin- $d_{5}$, paroxetine hydrochloride- $d_{4}$ and olanzapine- $d_{3}$, from Toronto Research Chemicals (Toronto, Canada); sarafloxacin- $d_{8}$ hydrochloride trihydrate, from Sigma-Aldrich; and sulfamethoxazole $-{ }^{13} \mathrm{C}_{6}$ and trimethoprim- ${ }^{13} \mathrm{C}_{3}$, from Isotope Cambridge Laboratories (Andover, MA, USA).

HPLC-grade methanol $(\mathrm{MeOH})$ and HPLC-grade acetonitrile $(\mathrm{ACN})$ were purchased from Scharlab (Barcelona, Spain). HPLC-grade water was obtained from purification of demineralised water in a Milli-Q Gradient A10 (Millipore, Bedford, MA, USA). Formic acid $(\mathrm{HCOOH}$, content $>98 \%)$, ammonium acetate $\left(\mathrm{NH}_{4} \mathrm{Ac}\right.$, reagent grade) and sodium hydroxide $(\mathrm{NaOH},>99 \%)$ were supplied by Scharlab (Barcelona, Spain).

Standards were dissolved in $\mathrm{MeOH}$, except macrolides, sulfonamides and lincosamides that were prepared in $\mathrm{ACN}$. The addition of $\mathrm{NaOH}$ was necessary for the proper dissolution of acidic analytes like quinolones. A mix of all compounds was prepared in $\mathrm{MeOH}$ and subsequently diluted with water to obtain working standard solutions. A mix of isotopically labeled internal standards (ILISs) was also prepared in $\mathrm{MeOH}$ and used as surrogate. All standard solutions and ILIS mix were stored in amber glass bottles at $-20{ }^{\circ} \mathrm{C}$ in a freezer.

Cartridges used for SPE were Oasis HLB $(60 \mathrm{mg})$ from Waters (Milford, MA, USA).

\subsection{Instrumentation}

Ultra-high performance liquid chromatography-tandem mass spectrometry (UHPLC) analysis was carried out using an Acquity UPLC system (Waters, Milford, MS, USA), equipped with a binary solvent pumping. In the first monitoring, chromatographic separation of the 20 pharmaceuticals was achieved using an Acquity UPLC BEH column, $1.7 \mu \mathrm{m}, 50 \mathrm{~mm} \times 2.1 \mathrm{~mm}$ (i.d.) (Waters). Later, when the number of compounds increased up to 47 , a longer column (Acquity UPLC HSS T3, $1.8 \mu \mathrm{m}, 100 \mathrm{~mm} \times 2.1 \mathrm{~mm}$ (i.d.)) was required for a satisfactory separation of all analytes but maintaining similar chromatographic runs. The LC system was interfaced to a TQD (triple quadrupole) mass spectrometer with an orthogonal electrospray ionization source Z-spray (Waters Corp.). MS/MS analysis was performed under selected reaction monitoring (SRM) mode, working in positive and negative ionization modes simultaneously. Chromatographic and mass spectrometry conditions can be found in detail in our previous papers (Gracia-Lor et al., 2010, 2011).

\subsection{Analytical procedure}

Water samples were extracted as described in Gracia-Lor et al. (2010, 2011). Briefly, the procedure was as follows: $100 \mathrm{~mL}$ water sample $(100 \mathrm{~mL}$ effluent wastewater (EWW) or 20 
$\mathrm{mL}$ influent wastewater (IWW) diluted with water to $100 \mathrm{~mL}$ ) spiked with the ILIS mix working solution was passed through the Oasis HLB cartridge, previously conditioned. Analytes were eluted with $5 \mathrm{~mL} \mathrm{MeOH}$ and the extract was evaporated and reconstructed with $1 \mathrm{~mL} \mathrm{MeOH}-$ water $(10: 90, v / v)$. Finally, $20 \mu \mathrm{L}$ of the final extract were injected in the UHPLC-MS/MS system. Quantification was made using calibration standards prepared in solvent, based on relative responses analyte/ILIS or on absolute analyte responses, depending on whether ILIS was used for correction or not. All methods applied were previously validated (Gracia-Lor et al., 2010, 2011).

\subsection{Sampling}

EWW and IWW samples were collected along 2008 and 2009. They were obtained from three WWTPs (Castellon de la Plana, Benicassim and Burriana) of the Castellon province (Spanish Mediterranean area). These WWTPs are designed to treat wastewaters (urban 0 mixed urban and industrial) operating with secondary treatment using conventional activated sludge. At present, the Castellon de la Plana WWTP has a tertiary treatment operating with sand filtration and ultraviolet irradiation, but it was not operating when the monitoring was carried out. Castellon de la Plana WWTP has a population equivalent of 265,000 inhabitants, while Benicassim and Burriana WWTPs serve to a population around 18,000 and 35,000 inhabitants. For each plant, 24-h composite untreated (influent) and treated wastewater samples (effluent) were obtained. Samples were frozen and stored at $-18{ }^{\circ} \mathrm{C}$ until analysis.

Sampling was carried out in two campaigns. In the first monitoring, samples were collected along one complete week in June 2008 and in January 2009 and the occurrence of 20 pharmaceuticals was investigated (Gracia-Lor et al., 2010). In the second monitoring, in the light of the results obtained, the number of investigated compounds was increased up to 47 in order to have a wider knowledge of the presence of pharmaceuticals in wastewaters. Most of pharmaceuticals added in the second monitoring corresponded to antibiotics. In this case, only EWW and IWW samples from the Castellon de la Plana WWTP (the main town of the Castellon province) were analyzed as no significant differences between the three studied WWTPs were observed and this treatment plant serves a larger population. 24-h Composite samples (IWW and EWW) were collected during one complete week in April 2009 and October 2009.

\section{Results and discussion}

\subsection{First monitoring}

First of all, a group of 20 pharmaceuticals were selected including the most consumed active principles with medical prescription in Spain (Ministry of Health, 2008, 2009). Several compounds with low official sales volumes (in terms of medical prescription) but frequently detected in urban wastewater as reported by other authors (Ternes, 2001; Gros et al., 2006; Hernando et al., 2007; Pedrouzo et al., 2007) were also included (e.g. diclofenac, naproxen or 
bezafibrate). In addition, two metabolites were considered: salicylic acid, which is the main metabolite of acetylsalicylic acid, and 4-aminoantipyrine, which is a metabolite of dipyrone. These metabolites were selected because they had been frequently determined in the aquatic environment (surface water and wastewater) according to scientific literature (Ternes et al., 2001; Heberer, 2002; Metcalfe et al., 2003; Wiegel et al., 2004). Thus, 20 pharmaceuticals for human use were selected (Table 1). Target analytes represented a broad range of chemicals classes including analgesic and anti-inflammatory, cholesterol lowering statin drugs, lipid regulators, antidepressants, anti-ulcer agents, psychiatric drugs, ansiolitics and cardiovasculars.

In total, 84 wastewater samples were analyzed in this monitoring, and collected from three WWTPs of the Castellon province. Sample collection was performed in summer 2008 (June) and winter 2009 (January). Table 1 shows the percentage of positive findings of the selected compounds, as well as median concentrations in IWW and EWW analyzed during this period.

13 out of 20 compounds were detected in IWW. All 13 pharmaceuticals were identified in more than $95 \%$ of the samples, with the exception of salicylic acid and pravastatin, the latest only being present in $26 \%$ of IWW samples. Analgesics/anti-inflammatories and lipid regulators were the most commonly detected groups. Moreover, the highest values in this type of samples corresponded to salicylic acid, acetaminophen and ibuprofen (these three compounds belong to the anti-inflammatory therapeutic group) with maximum levels of 277,201 and $40 \mu \mathrm{g} \mathrm{L}^{-1}$, and median concentration of $35.1,44.8$ and $12.4 \mathrm{\mu g} \mathrm{L}^{-1}$, respectively. Quantification of the samples with high analyte levels (typically above $100 \mu \mathrm{g} \mathrm{L}^{-1}$ ) required an additional analysis with previous dilution of the sample before the SPE step.

When comparing the percentage of positive findings in IWW collected in summer and in winter, no relevant differences were found. However, when comparing the maximum levels found, higher concentrations were observed for some compounds in the winter samples. For example, in the case of acetaminophen, salicylic acid and ibuprofen, maximum concentrations increased from 84 to $201 \mu \mathrm{g} \mathrm{L}^{-1}$, from 47 to $277 \mu \mathrm{g} \mathrm{L}^{-1}$, and from 20 to $40 \mu \mathrm{g} \mathrm{L}^{-1}$, respectively. For the rest of compounds, no relevant variations in concentrations were observed. 


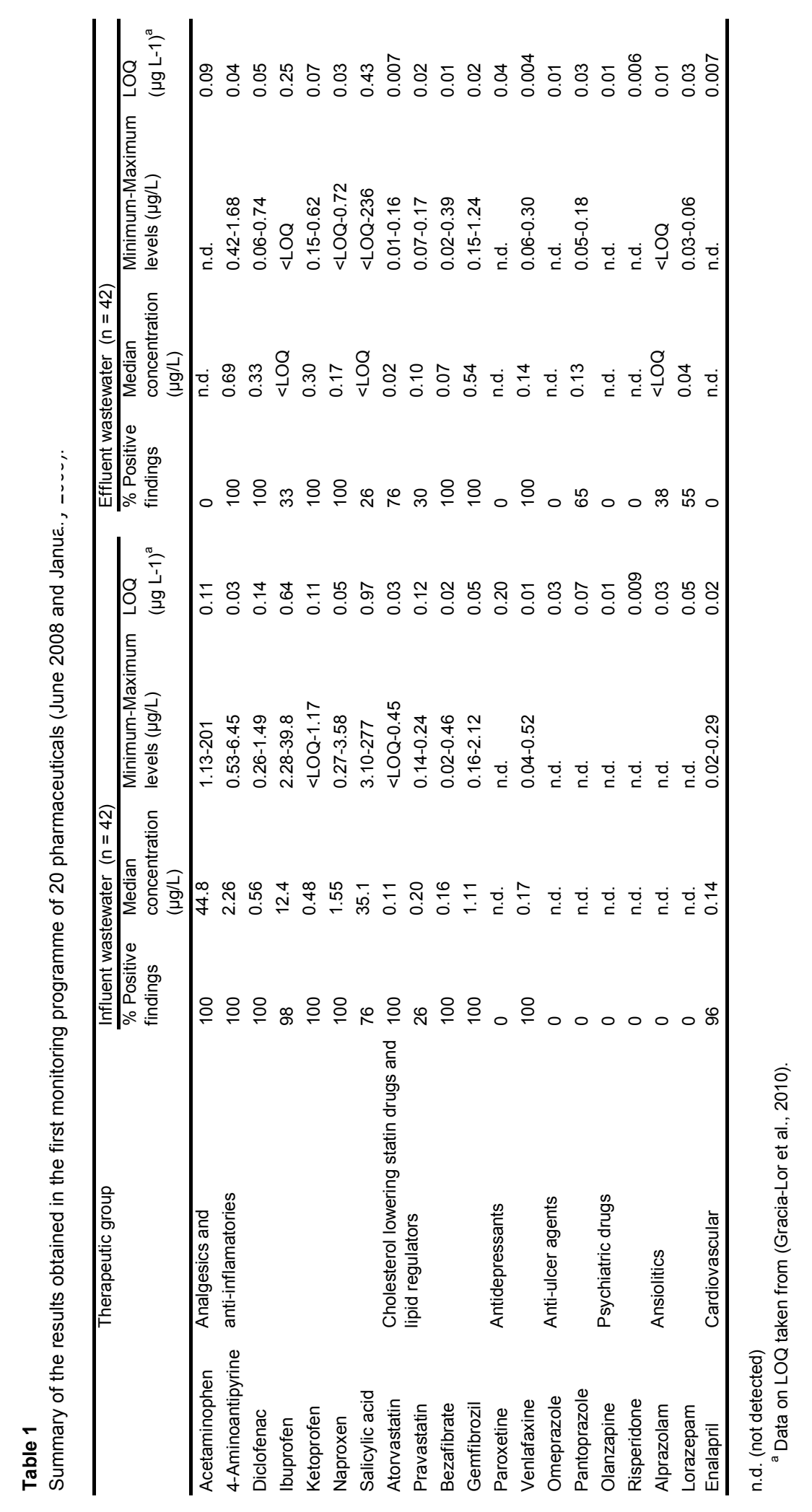


Regarding EWW, up to 14 target compounds were detected. Analgesic and antiinflamatories were frequently found (the exception was acetaminophen, which was never detected in the EWW samples in contrast to IWW where it was present in the $100 \%$ of samples). Cholesterol lowering statin drugs and lipid regulators were also found in a high number of samples but, with the exception of gemfibrozil, their median concentrations were below $0.10 \mu \mathrm{g} \mathrm{L}^{-1}$. Other compounds frequently detected were venlafaxine, pantoprazole and lorazepam.

The removal of pharmaceuticals during wastewater treatment was estimated from concentration data in IWW and EWW. Considering that pharmaceuticals have rather different physico-chemical characteristics, their removal during treatment is expected to be diverse. In the literature, the removal efficiency is generally computed as the percentage of reduction between the dissolved aqueous phase concentration of the contaminant in the influent and the dissolved aqueous phase concentration of the contaminant in the effluent. Except for a few studies, pharmaceutical concentrations in sludge or suspended solid are generally not considered nor measured, probably because of the difficulty to sample and to analyze such complex matrices (Miège et al., 2009). However, the screening of sewage sludge showed that these micro-pollutants are very present in this medium. This indicates that even good removal rates obtained in aqueous phase (i.e. comparison of influent and effluent wastewater concentrations) do not imply degradation to the same extent (Jelic et al., 2011). When comparing pharmaceutical concentrations in IWW and EWW, like in this work, lower levels in EWW would be interpreted as a removal of the compound in the WWTP. This fact might be due to different factors like chemical and physical transformations, biodegradation and sorption to the solid matter. Thus, the conversion of a given pharmaceutical to compounds other than the analyzed one would lead to lower pharmaceutical levels in EWW concluding that an "apparent" removal takes place.

In this work, acetaminophen, enalapril and ibuprofen were completely removed during the treatment processes (present in $100 \%$ and $96 \%$ of IWW samples, and never detected in the EWW samples), while the antidepressant venlafaxine, lipid regulator compounds, as well as analgesic and anti-inflammatory pharmaceuticals (with the exception of acetaminophen and ibuprofen) were detected in all EWW samples, although at concentrations lower than in IWW. On the other hand, some pharmaceuticals were not detected in IWW but they were present in EWW. This behavior was observed for pantoprazole and for the ansiolitic compounds alprazolam and lorazepam. This is in agreement with previous studies where some compounds were reported to be more abundant in effluents than in influents (Lacey et al., 2008; Gros et al., 2010; Jelic et al., 2011). In the case of the ansiolitic compounds, they were detected at very low concentrations in EWW (around or below the LOQ level). Maybe they were also present in the IWW samples but could not be detected due to the lower sensitivity of the method in this type of waters. The higher complexity of the influents leads to strong matrix effects (commonly ionization suppression), which can hamper the detection of some analytes at very low levels. 
The absence of ansiolitic compounds in the IWW might be also due to the enzymatic cleavage of the compound glucuronides and other conjugated metabolites and the subsequent release of the parent compound during the treatment process (Vieno et al., 2007; Lacey et al., 2008; Gros et al., 2010).

Predicting the removal efficiencies of compounds during treatment processes is quite difficult because they are significantly affected by the specific operating conditions of each WWTP. However, some information can be obtained from the data reported by others on the behavior of pharmaceuticals during the treatment processes. For instance, analgesics and antiinflammatory pharmaceuticals have been detected in the aquatic environment in a broad number of studies. Within this group, our data showed that acetaminophen was removed by the three WWTPs. For salicylic acid, an efficient removal was also obtained in contrast to diclofenac, ketoprofen and naproxen that seemed to persist to the water treatment, although their levels in EWW were lower than in IWW. This behavior is consistent with scientific literature (Heberer, 2002; Gros et al., 2010).

In the case of lipid regulators and cholesterol lowering statin drugs, they showed a variety of removal rates between $30 \%$ and $100 \%$ which is in fairly good agreement with previous studies (Jelic et al., 2011). In our case, the highest levels and frequency of detection were found for lipid regulators, especially for gemfibrozil.

Comparing the three studied WWTPs, no significant differences in terms of removal efficiencies were observed for the analyzed compounds. This is because they work at similar operational conditions.

\subsection{Second monitoring}

A notable number of compounds (around 30 antibiotics and a cholesterol lowering statin drug) were added to the target list of our previous method in order to have a more realistic knowledge of the presence of pharmaceuticals in the environment. Many antibiotics were included due to the special concern on their potential negative effects on the aquatic environment, whereas simvastatin, a cholesterol statin drug, was added to the list due to its increased consumption with medical prescription.

As differences among the three WWTPs were hardly observed in the first survey, in the second monitoring only the Castellon de la Plana WWTP was monitored, in two different seasons: spring (April 2009) and autumn (October 2009). This treatment plant was selected because it serves the largest population of the Castellon province (Table 2). Moreover, data obtained in the first monitoring revealed that the samples from this treatment plant typically presented the highest pharmaceutical levels. In this second monitoring, 28 wastewater samples 
(14 IWW and 14 EWW) were collected and analyzed (Table 3), corresponding to one whole week of April 2009 and one whole week of October 2009.

Table 2

Characteristics of the Castellon de la Plana treatment plant.

\begin{tabular}{|c|c|c|c|c|c|c|c|c|}
\hline WWTP & $\begin{array}{l}\text { Population } \\
\text { (he) }\end{array}$ & $\begin{array}{l}\text { Type of } \\
\text { treatment }\end{array}$ & $\begin{array}{l}\text { Type of } \\
\text { wastewater } \\
\text { treated }\end{array}$ & $\begin{array}{l}\text { Designed treatment } \\
\text { capacity }\left(\mathrm{m}^{3} \mathrm{~d}^{-1}\right)\end{array}$ & $\begin{array}{l}\text { Average flow } \\
\text { (m3/day) }\end{array}$ & $\begin{array}{l}\text { Minimum flow } \\
\text { estimated (L/s) }\end{array}$ & $\begin{array}{l}\text { Maximum flow } \\
\text { estimated (L/s) }\end{array}$ & Sampling \\
\hline $\begin{array}{l}\text { Castellon de } \\
\text { la Plana }\end{array}$ & 265,000 & Secondary $^{a}$ & $\begin{array}{l}\text { Urban and } \\
\text { industrial }\end{array}$ & 42,000 & 36,000 & 139.06 & 752.31 & $\begin{array}{l}\text { Time-proportional } \\
\text { composite (every } \\
60 \text { minutes) }\end{array}$ \\
\hline
\end{tabular}

${ }^{a}$ Secondary treatment was applied at the time of the monitoring was performed. At present, a tertiary treatment is applied.

In IWW, for those 20 pharmaceuticals also analyzed in the first monitoring, no relevant differences were observed except for diclofenac, which showed a lower frequency of detection. Similarly to the previous study, the highest concentrations in IWW were found for acetaminophen (134 $\left.\mathrm{g} \mathrm{L}^{-1}\right)$, salicylic acid $\left(64 \mu \mathrm{g} \mathrm{L}^{-1}\right)$ and ibuprofen $\left(19 \mu \mathrm{g} \mathrm{L}^{-1}\right)$. As pointed out before, these compounds are frequently prescribed but they can also be acquired without medical prescription, the so-called "over the - counter" (OTC) drugs.

In the case of antibiotics, it is difficult to establish a general trend for each group. As shown in Table 3, 9 out of 26 selected antibiotics were detected in the influent samples. Among them, seven compounds (ciprofloxacin, clarithromycin, norfloxacin, ofloxacin, pipemidic acid, sulfamethoxazole and trimethoprim) were detected in all the samples. On the contrary, lincomycin, which can be used in both human and veterinary medicine, and sulfathiazole were detected in around 20\% of IWW. Except for ciprofloxacin, antibiotic median concentrations in IWW did not exceed $1 \mu \mathrm{g} \mathrm{L}^{-1}$.

Regarding EWW, our data suggest that elimination of most of the compounds analyzed is incomplete. Again, we may distinguish different behaviors. First of all, there is a group of compounds that were fully eliminated in the treatment plant (i.e. acetaminophen, enalapril, ibuprofen, salicylic acid). These results are in agreement with those reported by other authors (Gros et al., 2010) and supported the behavior observed in the first monitoring, with slight differences observed for salicylic acid. On the other hand, there are several compounds partly removed by the treatment processes. For these compounds, concentrations after treatment were normally lower than in IWW, but they were still present in the EWW analyzed. This is the case of most lipid regulators and anti-inflammatory drugs. In some particular cases, e.g. gemfibrozil, concentrations were slightly higher in the effluent. Another group of pharmaceuticals included those compounds that showed poor or non elimination in the treatment plant, as some macrolide antibiotics, ansiolitics and the anti-ulcer agent pantoprazole, which presented even higher percentages of positive findings in EWW than in IWW. This fact has been previously reported in other studies (Göbel et al., 2007; Gros et al., 2010). As pointed out before, this phenomenon might be explained by the higher LOQs in IWW compared to EWW, or by the release of the parent compound from glucuronides or other conjugated 
metabolites during the treatment process. Finally, several target analytes were never found either in IWW or EWW. It was not expected for those compounds such as simvastatin, omeprazole or paroxetine that belong to the list of the most consumed pharmaceuticals in Spain with medical prescription. Their absence might be explained because their excretion was mainly as metabolites or due to the parent compound transformation/degradation in the sewer system. Thus, searching for metabolites and/or transformation products of these compounds seems necessary to evaluate their impact into the aquatic ecosystem.

Concerning sulfonamide antibiotics, only sulfamethoxazole was detected in EWW. In fact, it was present in $100 \% \mathrm{EWW}$ analyzed although at very low levels, below $0.06 \mu \mathrm{g} \mathrm{L}^{-1}$. Some contradiction exists about its removal (Le-Minh et al., 2010) as some studies have observed an effective removal (Choi et al., 2008) while others not (Brown et al., 2006). This fact might be explained by differences in operational conditions of each WWTP. 


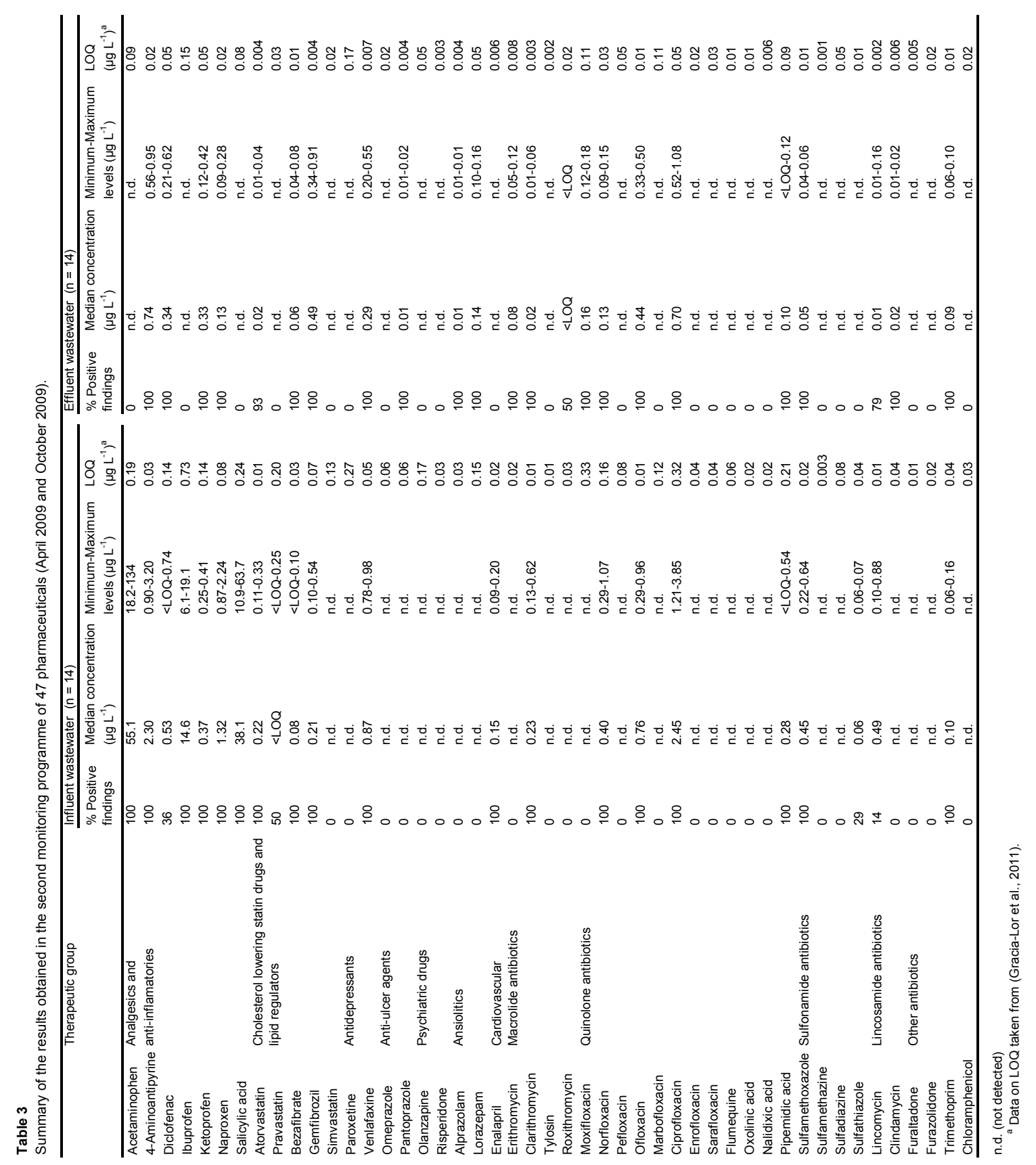


The presence of trimethoprim is usually related to the detection of sulfamethoxazole since these pharmaceuticals are often administered together. In agreement with other studies (Ternes, 2001; Gros et al., 2010; Jelic et al., 2011), the removal of trimethoprim during the wastewater treatment was incomplete.

In the case of macrolide antibiotics, all compounds belonging to this therapeutic group were detected in EWW, except for tylosin which was never found. Among them, the percentage of positive findings and concentrations may differ due to their different consumption pattern. The incomplete removal of macrolide antibiotics by WWTP is in agreement to previous works (Clara et al., 2005; Göbel et al., 2007). In our study, erithromycin and roxithromycin were present in the effluent samples, but absent in the corresponding influent. Some authors suggest that this might be due to the release of these compounds from faeces during the biological treatment (Göbel et al., 2007).

Regarding quinolone antibiotics, they have been frequently detected in wastewaters from several countries, especially norfloxacin and ciprofloxacin. In our case, 5 out of 12 compounds that belong to this group were found in EWW (see Table 3).

The results obtained in this monitoring work support the interest for including antibiotics when monitoring pharmaceuticals in wastewater, as they have been found rather frequently in the samples.

In all samplings carried out, samples were collected during one complete week. In general, concentration of pharmaceuticals did not significantly change along the week. This indicates that the consumption of the studied compounds is quite constant over the week in contrast to illicit drugs, which consumption clearly increases during the weekends and in special events (Bijlsma et al., 2009).

In this survey, a more complete seasonal variation analysis could be made for the Castellon de la Plana WWTP, which was the only one sampled in all monitoring programmes (four seasons, from summer 2008 to autumn 2009). Regarding the 20 most consumed pharmaceuticals, initially selected, they did not show big variations in median concentrations over the year (Fig. 1a and b). This is in accordance to their use, which is rather constant along the year. For a few compounds higher concentrations were found in winter for IWW (acetaminophen, salicylic acid, naproxen or diclofenac). These compounds are analgesic and anti-inflammatory pharmaceuticals, which are consumed along the whole year, but especially in winter. 
(a)

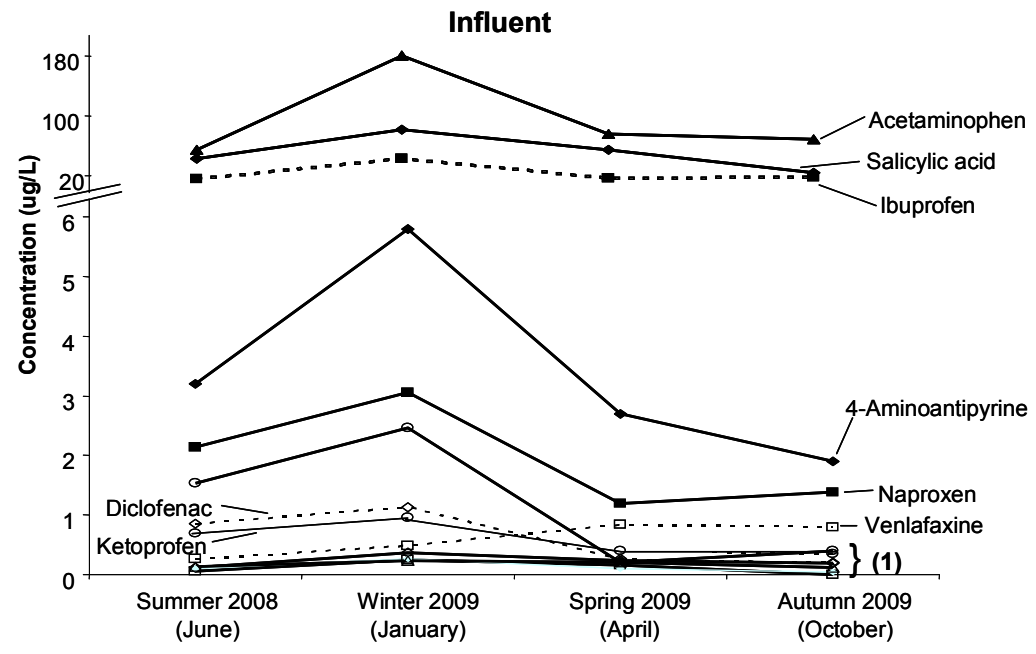

(1) Atorvastatin Pravastatin Bezafibrate Gemfibrozil Enalapril

(b)

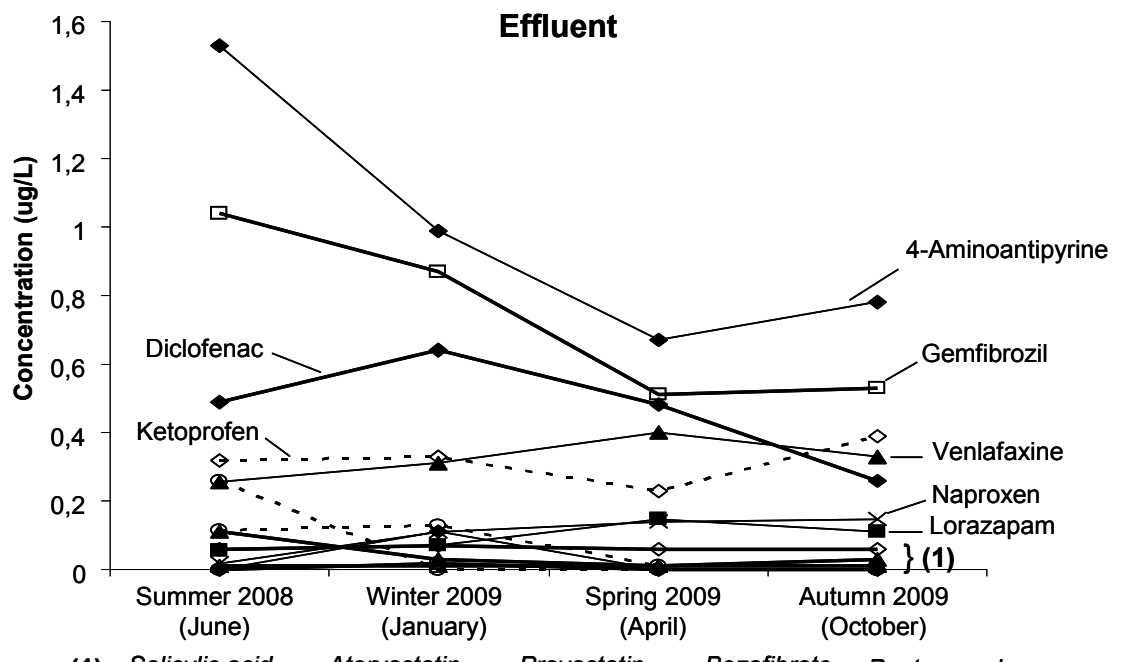

(1) Salicylic acid Atorvastatin Pravastatin Bezafibrate Pantoprazole

Figure 1. Median pharmaceutical concentration in the influent (a) and in the effluent (b) of the Castellon de la Plana WWTP monitored along four seasons.

Regarding antibiotics, a comparison between spring and autumn concentrations was made, as they were only determined in these two seasons (Fig. 2a and b). We did not observe relevant differences, as the same compounds were detected in both seasons at similar median concentrations. However, it is noteworthy that antibiotic concentrations were notable lower than for the rest of pharmaceuticals, probably because they are less consumed. The only exception was ciprofloxacin. 
(a)

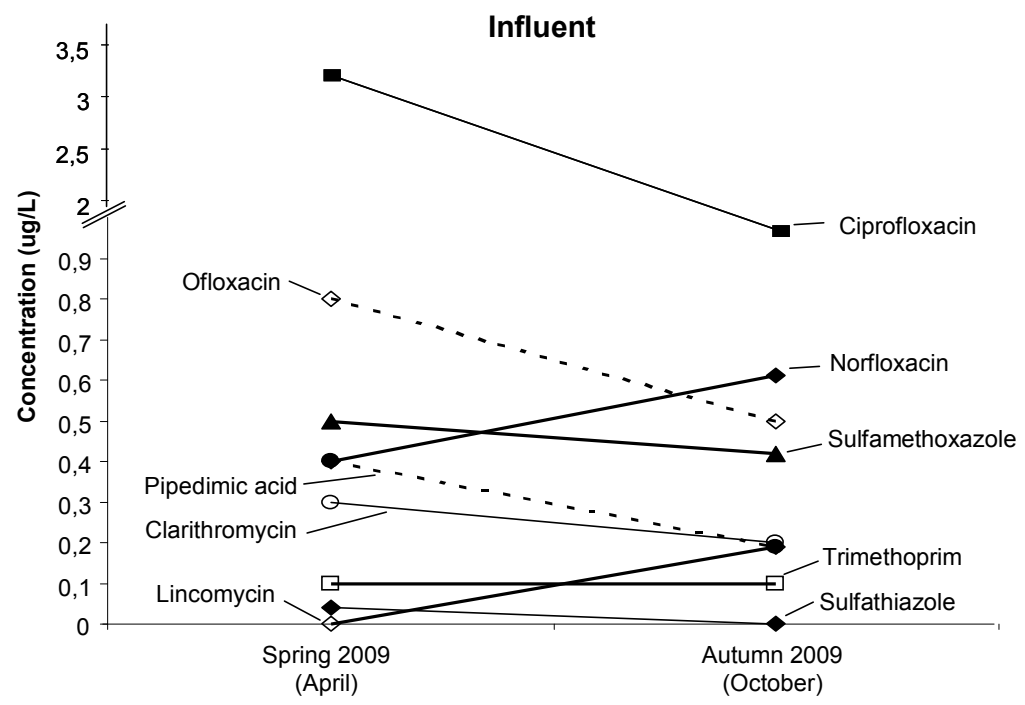

(b)

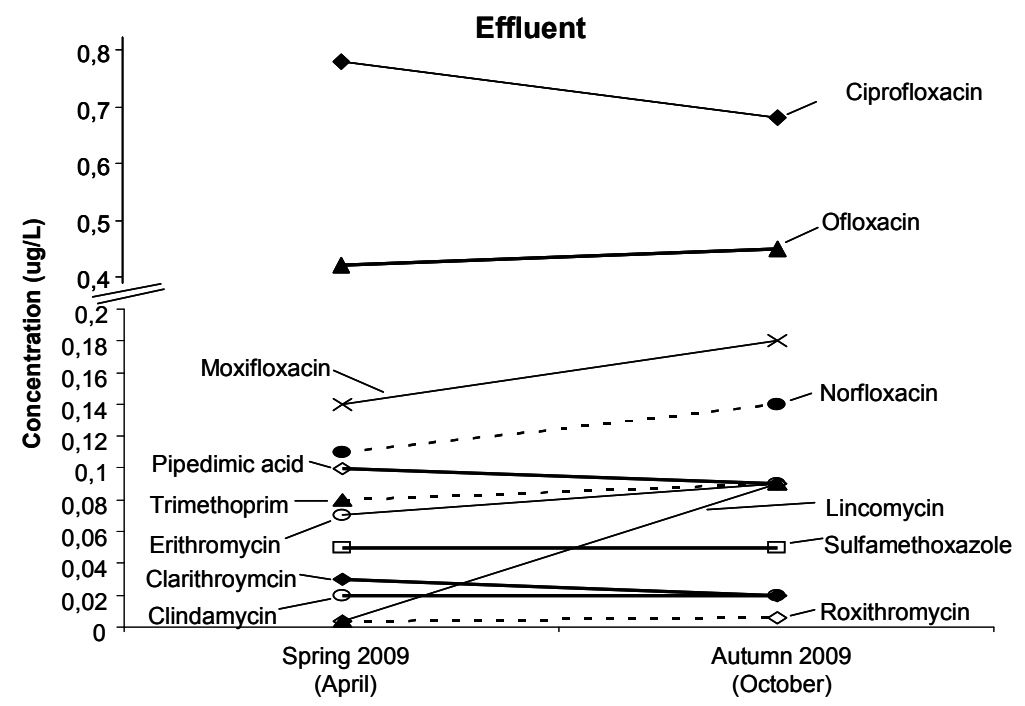

Figure 2. Median antibiotics concentration in the influent (a) and in the effluent (b) of the Castellon de la Plana treatment plant monitored in spring and autumn 2009.

The removal efficiency (RE) of the Castellon de la Plana WWTP is illustrated in Fig. 3. Those pharmaceuticals that were not detected in influent and in effluent wastewater samples (e.g. simvastatin, paroxetine, pefloxacin, etc.) have been omitted in this figure. RE values were calculated as the ratio between the median concentration levels of each pharmaceutical in influents and effluents. Data from samples collected along a whole week in April 2009 have been used in this figure. This WWTP seemed to have good removal efficiency for most analgesics/anti-inflammatories like acetaminophen, ibuprofen, naproxen or salicylic acid (RE around $100 \%$ ). As regards the four cholesterol lowering statin drugs/lipid regulators detected in wastewater, two of them seemed to be efficiently removed (atorvastatin, pravastatin), while partial removal was suggested for bezafibrate (RE around 40\%) and no removal was observed for gemfibrozil. The cardiovascular enalapril was also efficiently removed. 
In relation to antibiotics, 6 out of 13 compounds detected in wastewater were rather efficiently removed in the WWTP, whereas ofloxacin and trimethoprim showed RE between $20 \%$ and $40 \%$. However, negative RE were observed for 5 antibiotics because these pharmaceuticals were not detected in IWW samples but were present in the corresponding EWW samples. In this case, it was not possible to calculate the RE actually, and a reference value $(-100 \%)$ was given in order to show their behavior in the figure. The same situation was observed for three more compounds (pantoprazole, alprazolam and lorazepam) that were not found in IWW although they were detected in EWW (all compounds marked as ( ${ }^{*}$ ) in Fig. 3). As previously stated, this situation might be due to the non-detection in IWW as a consequence of the higher complexity of this matrix, with typically higher matrix suppression, and the higher LOQs resulting in IWW. It must be taken into account that concentration levels found in EWW were normally low for all those compounds. Thus, they might be present at low levels in the IWW as well, and might not have been detected. Therefore, this assigned arbitrary value of $100 \%$ for al these 8 compounds might be questioned.

In the case of gemfibrozil and diclofenac, negative RE values were due to a slight increase of their concentration during the treatment process, i.e., they were detected at higher concentration levels in the effluent. 


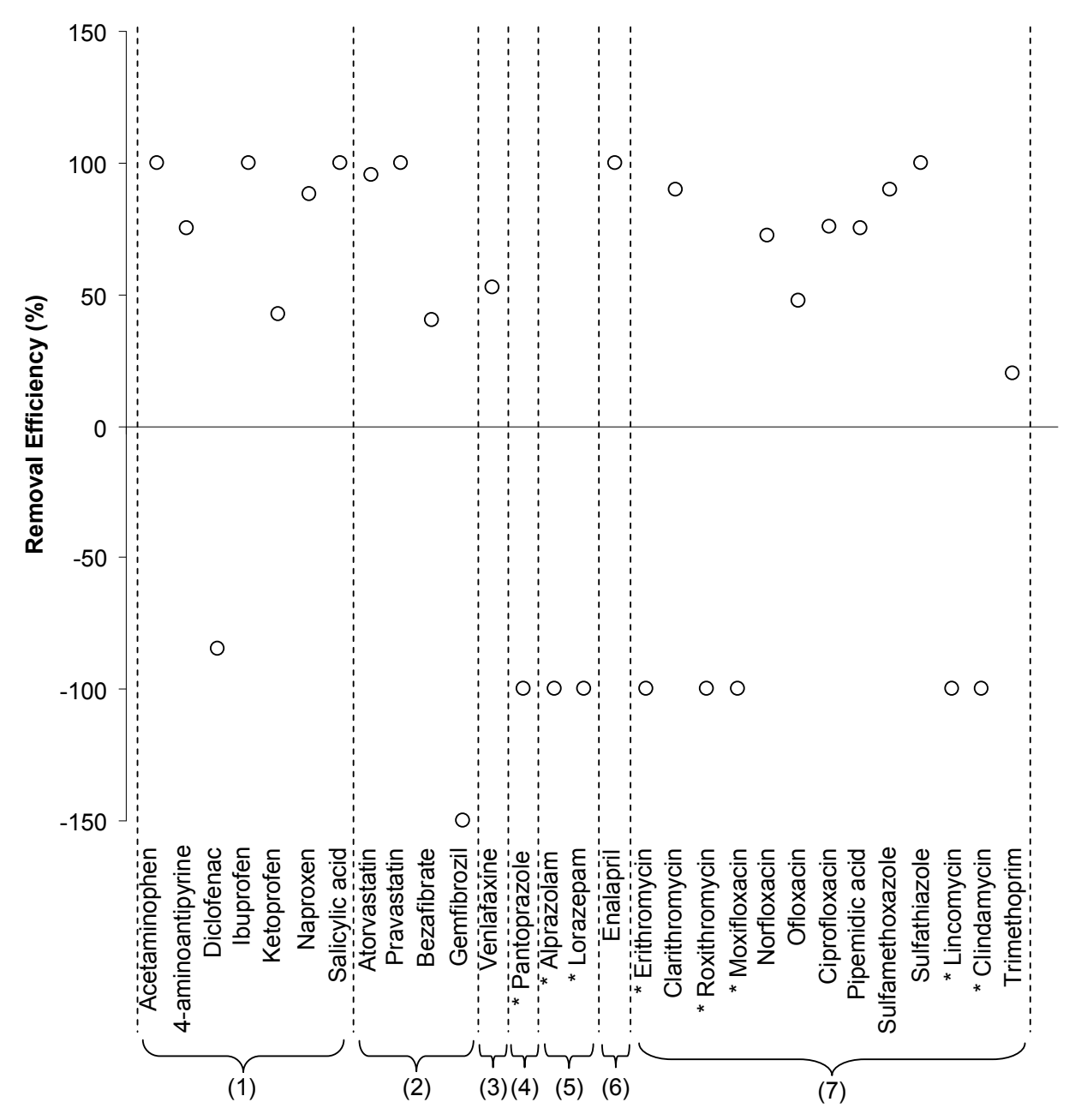

* Compounds not detected in IWW but present in the EWW samples

Figure 3. Removal efficiency of the Castellon de la Plana WWTP. (Data from April 2009). (1) Analgesics and anti-inflammatories, (2) cholesterol lowering statin drugs and lipid regulators, (3) antidepressants, (4) anti-ulcer agents, (5) ansiolitics, (6) cardiovasculars, and (7) antibiotics.

\section{Conclusions}

In this study, a monitoring of around 50 pharmaceuticals has been made in IWW and EWW from three different WWTPs. Up to 17 compounds were detected in both IWW and EWW indicating that conventional treatment processes do not completely remove these micropollutants. Among them, analgesics and anti-inflamatories, lipid regulators as well as quinolone and macrolide antibiotics were the major groups found.

Selected pharmaceuticals could be divided into four groups according to their behavior in WWTPs: a few compounds were completely removed during the treatment processes (e.g. acetaminophen, enalapril, ibuprofen); another group of analytes were not fully removed, although their concentrations after treatment were significantly lower than in influent (e.g. lipid regulators). A third group of compounds were not detected in IWW but were present in the 
EWW samples (e.g. ansiolitics and macrolide antibiotics). Finally, some pharmaceuticals were never detected in either IWW or EWW (e.g. simvastatin, paroxetine, sulfamethazine).

Searching for metabolites may offer valuable information (Tarcomnicu et al., 2011), especially for those analytes never found in wastewater despite they were frequently used. Future research will be directed towards the investigation of metabolites by using quadrupole time of flight (QTOF) mass spectrometry. In those particular cases where pharmaceuticals were not detected in IWW but detected in the corresponding EWW samples, QTOF would also be an ideal approach to identify glucuronide and conjugated metabolites, if present in IWW. Thus, the occurrence of metabolites and conjugated compounds could be studied by this technique.

Seasonal variation in terms of median concentration values was not clearly observed in IWW and EWW. However, when comparing the maximum levels reached, higher concentrations were found in winter (January 2009), especially for analgesic and anti-inflamatory pharmaceuticals, possible due to a higher consumption during this period of the year to treat, for example, seasonal flu.

\section{Acknowledgements}

The authors are very grateful to FACSA, especially to Carlos Ferrer, for providing wastewater samples and information about the treatment plants monitored. The LC-MS/MS instrument (Waters, TQD) from Serveis Centrals d'Instrumentació Científica (SCIC) of University Jaume I has been used in this work. The authors acknowledge the financial support of Generalitat Valenciana as research group of excellence PROMETEO/2009/054. E. Gracia-Lor is very pleased to University Jaume I for her pre-doctoral grant.

This work has been developed under financial support of the Ministry of Education and Science, Research Projects CTM-2006-07711 and CTQ-2009-12347.

\section{References}

Bijlsma, L., Sancho, J.V., Pitarch, E., Ibáñez, M., Hernández, F., 2009. Simultaneous ultra-high-pressure liquid chromatography-tandem mass spectrometry determination of amphetamine and amphetamine-like stimulants, cocaine and its metabolites, and a cannabis metabolite in surface water and urban wastewater. J.Chromatogr.A 1216, 3078-3089.

Brown, K.D., Kulis, J., Thomsom, B., Chapman, T.H., Mawhinney, D.B., 2006. Occurrence of antibiotics in hospital, residential, and dairy effluent, municipal wastewater, and the Rio Grande in New Mexico. Sci. Total Environ. 366, 772-783. 
Castiglioni, S., Bagnati, R., Fanelli, R., Pomati, F., Calamari, D., Zuccatto, E., 2006. Removal of pharmaceuticals in sewage treatment plants in Italy. Environ. Sci. Technol. 40, 357363.

Choi, K., Kim, Y., Park, J., Park, C.K., Kim, M., Kim. H.S., Kim. P., 2008. Seasonal variations of several pharmaceutical residues in surface water and sewage treatment plants of Han River, Korea. Sci. Total Environ. 405, 120-128.

Clara, M., Strenn, B., Gans, O., Martinez, E., Kreuzinger, N., Kroiss, H., 2005. Removal of selected pharmaceuticals, fragrances and endocrine disrupting compounds in a membrane bioreactor and conventional wastewater treatment plants. Water Res. 39, 4797-4807.

Heberer, T., 2002. Occurrence, fate, and removal of pharmaceutical residues in the aquatic environment: A review of recent research data. Toxicol. Lett. 131, 5-17.

Jelic, A., Gros, M., Ginebreda, A., Cespedes-Sánchez, R., Ventura, F., Petrovic, M., Barceló, D., 2011. Occurrence, partition and removal of pharmaceuticals in sewage water and sludge during wastewater treatment. Water Res. 45, 1165-1176.

Göbel, A., McArdell, C.S., Joss, A., Siegrist, H., Giger, W., 2007. Fate of sulfonamides, macrolides, and trimethoprim in different wastewater treatment technologies. Sci. Total Environ. $372,361-371$.

Gracia-Lor, E., Sancho, J.V., Hernández, F., 2010. Simultaneous determination of acidic, neutral and basic pharmaceuticals in urban wastewater by ultra high-pressure liquid chromatography-tandem mass spectrometry. J.Chromatogr.A 1217, 622-632.

Gracia-Lor, E., Sancho, J.V., Hernández, F., 2011. Multi-class determination of around 50 pharmaceuticals, including 26 antibiotics, in environmental and wastewater samples by ultrahigh performance liquid chromatography-tandem mass spectrometry. J.Chromatogr.A, 1218, 2264-2275.

Gros, M., Petrovic, M., Barceló, D., 2006. Development of a multi-residue analytical methodology based on liquid chromatography-tandem mass spectrometry (LC-MS/MS) for screening and trace level determination of pharmaceuticals in surface and wastewaters. Talanta $70,678-690$.

Gros, M., Petrovic, M., Ginebreda, A., Barceló, D., 2010. Removal of pharmaceuticals during wastewater treatment and environmental risk assessment using hazard indexes. Environ. Int. 36, 15-26

Hernando, M.D., Agüera, A., Fernández-Alba, A.R., 2007. LC-MS analysis and environmental risk of lipid regulators. Anal.Bional.Chem. 387, 1269-1285. 
Jones, O.A.H., Voulvoulis, N., Lester, J.N., 2005. Human pharmaceuticals in wastewater treatment processes. Crit. Rev. Environ. Sci. Technol. 35, 401-427.

Kümmerer, K., 2009a. Antibiotics in the aquatic environment- A review- Part I. Chemosphere $75,417-434$.

Kümmerer, K., 2009b. Antibiotics in the aquatic environment- A review- Part II. Chemosphere $75,435-441$.

Lacey, C., McMahon, G., Bones, J., Barron, L., Morrissey, A., Tobin, J.M., 2008. An LCMS method for the determination of pharmaceutical compounds in wastewater treatment plant influent and effluent samples. Talanta 75, 1089-1097.

Le-Minh, N., Khan, S.J., Drewes, J.E., Stuetz, R.M., 2010. Fate of antibiotics during municipal water recycling treatment processes. Water Res. 44, 4295-4323.

Miège, C., Choubert, J.M., Ribeiro, L., Eusèbe, M., Coquery, M., 2009. Fate of pharmaceuticals and personal care products in wastewater treatment plants - Conception of a database and first results. Environ. Pollut. 157, 1721-1726.

Metcalfe, C.D., Koenig, B.G., Bennie, D.T., Servos, M., Ternes, T.A., Hirsch, R., 2003. Occurrence of neutral and acidic drugs in the effluents of canadian sewage treatment plants. Environ. Toxicol. Chem. 22, 2872-2880.

Ministry of Health, 2008:

(http://www.msps.es/biblioPublic/publicaciones/recursos_propios/infMedic/docs/vol33_3 NotasInteres.pdf ) (accessed March 2011)

Ministry of Health, 2009:

(http://www.msc.es/biblioPublic/publicaciones/recursos_propios/infMedic/docs/vol33_3 NotasInteres.pdf) (accessed March 2011)

Nikolaou, A., Meric, S., Fatta, D., 2007. Occurrence patterns of pharmaceuticals in water and wastewater environments. Anal. Bioanal. Chem. 387, 1225-1234.

Pedrouzo, M., Reverté, S., Borrull, F., Pocurull, E., Marcé, R.M., 2007. Pharmaceutical determination in surface and wastewaters using high-performance liquid chromatography(electrospray)-mass spectrometry. J. Separ. Sci. 30, 297-303.

Suárez, S., Carballa, M., Omil, F., Lema, J.L., 2008. How are pharmaceutical and personal care products (PPCPs) removed from urban wastewaters? Rev. Environ. Sci. Biotechnol. 7, 125-138. 
Tarcomnicu, I., van Nuijs, A.L.N., Simons, W., Bervoets, L., Blust, R., Jorens, P.G., Neels, H., Covaci, A., 2011. Simultaneous determination of 15 top-prescribed pharmaceuticals and their metabolites in influent wastewater by reversed-phase liquid chromatography coupled to tandem mass spectrometry. Talanta $83,795-803$.

Ternes, T.A., 2001. Analytical methods for the determination of pharmaceuticals in aqueous environmental samples. Trends Anal. Chem. 20, 419-434.

Ternes, T.A., Bonerz, M., Schmidt, T., 2001. Determination of neutral pharmaceuticals in wastewater and rivers by liquid chromatography-electrospray tandem mass spectrometry. J.Chromatogr.A 938, 175-185.

Vieno, N., Tuhkanen, T., Kronberg, L., 2007. Elimination of pharmaceuticals in sewage treatment plants in Finland. Water Res. 41, 1001-1012.

Wiegel, S., Aulinger, A., Brockmeyer, R., Harms, H., Löffler, J., Reincke, H., Schmidt, R., Stachel, B., Von Tümpling, W., Wanke, A., 2004. Pharmaceuticals in the river Elbe and its tributaries. Chemosphere 57, 107-126.

Zuccato, E., Castiglioni, S., Bagnati, R., Melis, M., Fanelli, R., 2010. Source, occurrence and fate of antibiotics in the Italian aquatic environment. J. Hazard. Mater., 179, 1042-1048. 